\title{
A FORMAÇÃO DOS TRABALHADORES NA ESCOLA: ONDE ESTÁ O CENTRO DA DISPUTA?
}

Eveline Algebaile ${ }^{1}$

\section{Resumo}

Partindo da compreensão de que a formação dos trabalhadores na escola é um fenômeno mais amplo e complexo que a formação escolar dos trabalhadores, em sentido restrito, o artigo dá ênfase à necessidade de se tomar as relações escolares como objeto de conhecimento e ação. Nesse sentido, são discutidos, inicialmente, aspectos gerais da produção histórica da escola capitalista que determinam limitações estruturais para a formação dos trabalhadores, mesmo nos quadros nacionais em que as instituições escolares adquiriram material, funcional e pedagogicamente condições de realização mais favoráveis. Em seguida, são abordadas as especificidades da questão educacional no Brasil, em face de sua posição historicamente subordinada nas relações capitalistas, e são problematizadas as implicações dessas especificidades em termos da formação dos trabalhadores na escola. Por fim, são discutidos aspectos entendidos como decisivos para o entendimento e a disputa da formação humana e social que se dá na escala das relações escolares, formação que não diz respeito apenas aos filhos dos trabalhadores, mas a todos os segmentos de trabalhadores que participam da produção cotidiana da escola.

Palavras-chave: Educação brasileira; formação escolar; classe trabalhadora.

\section{The formation of workers at school: where is the dispute center?}

\begin{abstract}
Considering the comprehension that the formation of workers at school is a broader and more complex phenomenon than the school education of them, in restrict sense, the article emphasizes the necessity of take the school relations as object of knowledge and action. In this sense, it is discussed, initially, general aspects of the historical production of capitalistic school that determine structural limitations to the workers development/formation, even on the national scenarios where school institutions acquired material, functional and pedagogically, more favorable achievement ways. Afterwards, it is addressed the specificities of the educational issue in Brazil, in face of its position historically subordinate on capitalistic relations, and it is problematized the implications of these specificities in terms of the workers formation at school. At the end, it is discussed aspects that are considered decisive for the understanding and the dispute of the human and social formation which occurs in scale of the school relations, formation that does not concerns only to the
\end{abstract}

\footnotetext{
${ }^{1}$ Professora da Universidade do Estado do Rio de Janeiro. Membro do Grupo THESE - Projetos Integrados de Pesquisas sobre Trabalho, História, Educação e Saúde - UERJ-UFF-EPSJV/Fiocruz. Procientista UERJ e Bolsista do Programa Jovem Cientista do Nosso Estado, da FAPERJ.
} 
sons of workers, but to all the segments of workers that participate of the daily school production.

Keywords: Brazilian education; school education; working class.

\section{Introdução: Formação escolar dos trabalhadores e formação dos trabalhadores na escola: uma distinção necessária}

É possível que, em seu uso corrente, o termo "formação dos trabalhadores na escola" seja entendido como "formação escolar dos trabalhadores e de seus filhos", implicando delimitações conceituais e empíricas que dão maior destaque a aspectos mais diretamente relacionados à efetividade do plano formativo da escola, e deixando parcialmente ocultos ou secundarizados aspectos cruciais para a apreensão da escola como um âmbito de realização cotidiana de relações cuja incidência formativa excede, em muito, a aprendizagem prevista e planejada.

Esses dois termos, porém, designam objetos significativamente distintos, e o debate sobre as relações entre a formação dos trabalhadores e a escola requer que essa distinção fique minimamente clara desde o início.

Assim, proponho que, nos limites deste artigo, o termo formação escolar seja entendido como aquele que designa principalmente o processo de formação sistemática planejado e realizado pela escola, envolvendo tanto a apreensão de conteúdos, práticas, comportamentos e habilidades previstos no plano formativo escolar, quanto a progressão escolar coadunada com essa apreensão. Definido deste modo, o termo não necessariamente deixa fora da discussão as condições materiais e funcionais da escola, ou os demais processos e relações que nela ocorrem; mas esses aspectos tendem a ser considerados a partir de seus nexos mais diretos com as atividades-fim da instituição escolar.

Em sentido diverso, proponho que o termo formação na escola nos remeta a um plano mais amplo de abordagem das condições, relações e processos que, apesar de apresentarem nexos com o plano de ação formativa escolar, não se restringem a ele, fazendo da escola um âmbito vivo de relações que nos formam, por incidirem em nossos modos de ser, de sentir, de pensar e de agir no mundo, concorrendo, deste modo, para "sermos o que somos". 
Certamente, os dois termos, segundo as definições acima propostas, podem ser abordados em uma perspectiva crítica. O segundo, porém, de meu ponto de vista, é obrigatoriamente mais amplo e, no que diz respeito à dinâmica de produção histórico-social da escola e à sua compreensão e análise, precede o primeiro, ou seja, é histórica e estruturalmente precedente.

É importante também observar que esses termos, assim compreendidos, delineiam dois ângulos válidos e importantes de abordagem da escola e dos processos formativos a ela vinculados, ângulos aos quais correspondem certos aspectos específicos que é preciso conhecer e problematizar. O que os diferencia fundamentalmente, porém, não é a suposta exclusividade de aspectos que seriam específicos de cada ângulo, mas as posições e os pesos que os variados aspectos tendem a ter nas análises realizadas num ou noutro caso, de modo que, no primeiro caso (formação escolar), tende-se a enfatizar o que é mais correntemente entendido como "próprio da escola", enquanto que, no segundo caso (formação na escola), a atenção também se projeta, e com grande destaque, para aquilo que, não sendo formalmente "próprio da escola", ou não constituindo imediatamente o que se considera ser seu núcleo de ações fundamentais, insiste em habitá-la, tornando-a "o que de fato é", e não o que é formalmente previsto e definido sobre seu suposto "ser".

Como entendo que, na discussão sobre a formação dos trabalhadores, essas diferentes delimitações alteram significativamente o peso e a posição (de centralidade e de precedência) do que me parece ser crucial considerar, escolho não discutir a formação escolar, assumindo o risco de traduzir o tema da formação do trabalhador na escola em uma escala analítica mais ampla e, portanto, mais difusa.

Essa escolha, por sua vez, obriga-me a orientar o tema para um quadro de apreensão da realidade no qual o termo formação precisa ser relacionado ao processo amplo ao longo do qual vamos nos tornando o que somos, um tornar-se que, como nos alerta Thompson (2002a, 2002b e 2004), tem também um irredutível componente de fazer-se. Isto não significa secundarizar a formação escolar nesse processo formativo; significa reconhecer que a escola participa da formação dos sujeitos para além, muito além, do plano formativo escolar, em sentido restrito, que ocorre sistemática e cotidianamente com o seu funcionamento. Significa 
reconhecer, portanto, que o próprio plano formativo escolar tem sua forma real definida a partir das relações por meio das quais a escola se realiza. Assim, a escola que, nessa delimitação mais ampla, aparece como espaço de convívio cotidiano, revela-se como o lugar de uma experiência ${ }^{2}$ que participa de forma ampliada da nossa formação humana e social. E se queremos discutir "a formação do trabalhador na escola", circunscrever nossas indagações à escala da formação escolar em sentido restrito é insuficiente; precisamos projetá-las na escala larga dessa experiência.

Partindo dessas definições preliminares, busco discutir inicialmente, neste artigo, aspectos gerais da produção histórica da escola capitalista que determinam limitações estruturais para a formação dos trabalhadores, mesmo nos quadros nacionais em que as instituições escolares adquiriram material, funcional e pedagogicamente as mais favoráveis condições de desenvolvimento. Prossigo nessa discussão considerando as especificidades da questão educacional no Brasil, em face de sua posição historicamente subordinada nas relações capitalistas, e as implicações dessas especificidades em termos da formação dos trabalhadores na escola. Na sequência, problematizo aspectos que me parecem decisivos para avançarmos no entendimento e nas disputas dessa escala de formação, ou seja, a formação humana e social que se dá na escala das relações escolares e que não diz respeito apenas aos alunos, mas a todos os segmentos de trabalhadores que participam da produção cotidiana da escola.

\section{A escola e a formação dos trabalhadores no capitalismo: um acerto de contas} com as ilusões

Como mostram, por diferentes vias, as formulações de autores de perspectivas diversas, como Gramsci (2000a), Castel (1998), Donzelot (2001), Petitat (1994) e Varela (1991), a escola moderna não nasce como direito, mas como recurso estratégico de um Estado em constituição que, para firmar-se como instituição política em uma nova escala (a escala dos Estados nacionais) e segundo

\footnotetext{
${ }^{2}$ Tomamos aqui o termo experiência conforme as formulações de Thompson, que a entende como uma categoria "que compreende a resposta mental e emocional, seja de um indivíduo ou de um grupo social, a muitos acontecimentos inter-relacionados ou a muitas repetições do mesmo tipo de acontecimento" (Thompson, 1981, p.15).
} 
novas formas de legitimação do exercício de poder (fundadas em pressupostos racionais-legais), precisa desenvolver instituições que realizem com efetividade novas e mais complexas funções de dominação e controle da população e do território.

Os sentidos de direito surgem gradualmente, conforme os diferentes segmentos sociais vão percebendo as incidências da escolarização sobre as condições individuais e coletivas de participação econômica, política e social, envolvendo alterações importantes nos modos de se apreender as mediações da escola não apenas em relação aos nexos entre o presente e o futuro, mas também em relação aos critérios e processos de diferenciação social.

A emergência dos sentidos de direito não chega a transformar o caráter geral da escola capitalista, que segue historicamente consolidando suas funções de classificação e hierarquização social. Mas essa emergência instaura no próprio processo de produção da escola um núcleo de tensões extremamente importantes para os desdobramentos seguintes dessa instituição.

A partir de então, e conforme o sentido de direito em relação à educação escolar se torna mais presente e elaborado, as funções propriamente capitalistas das instituições escolares não podem mais se realizar sem levar em conta as demais expectativas e suas condições de disputarem o próprio caráter geral da escola.

De outro lado, se é verdade que, nesse processo, as funções tipicamente capitalistas da escola podem ser relativamente abaladas, é igualmente verdade que as tensões entre propósitos de dominação e sentidos de direito não se dão na forma de uma disputa binária entre duas forças homogêneas e completamente opostas. Ou seja, parte das estratégias de afirmação da hegemonia das funções de dominação sobre os sentidos de direito se dá exatamente a partir de formas de incorporação, transformismo e conversão das próprias noções de direito à educação, de modo a atenuar sua potência disruptiva e reforçar a manutenção da ordem de dominação.

Assim, no curso da consolidação da escola como instituição social especializada nas sociedades capitalistas, a noção de direito à educação vem sendo historicamente incorporada e convertida, ainda que parcialmente e com oscilações e contradições, em um recurso estratégico de legitimação, 
mascaramento, reabilitação e fortalecimento das funções de dominação e controle, de modo que as disputas pelo caráter da escola não se dão numa linha de guerra clara entre dominação e direito, mas num terreno difuso e pantanoso em que a própria noção de direito é incisivamente tensionada, distorcida e disputada de modo a fortalecer a supremacia da dominação.

Um exemplo disto, do meu ponto de vista, pode ser percebido no uso persistente de uma noção positivada de universalização da escola nas lutas e debates relacionados ao direito à educação.

As experiências de seguidas gerações e diversas formulações críticas clássicas - como as de Gramsci (2000a), sobre a "marca de classe" da escola, e as de Bourdieu (1998), sobre suas formas de reproduzir diferenças sociais mostraram à exaustão que os processos de expansão escolar no modo de produção capitalista envolvem seguidamente os mais variados mecanismos de diferenciação por meio dos quais a propalada universalização da escola não se realiza como garantia do mesmo tipo de escola para todos. A análise da expansão da oferta escolar, nestes casos, mostra o quanto o nexo constitutivo entre universalização e diferenciação possibilita conjugar a expansão da escola com a manutenção de suas funções classificatórias.

Malgrado a força esclarecedora desses estudos, uma concepção genérica de universalização - que não dá suficiente evidência aos componentes ideológicos que ajudam esse constructo a anunciar igualdade onde e quando desigualdades estão sendo recriadas - segue dominando os modos contemporâneos de apresentar os desafios e as conquistas fundamentais em relação à educação escolar.

A frequência com que desigualdades escolares são tratadas como meras diferenças ou entendidas como algo decisivamente em vias de superação, fazendo parecer que toda e qualquer expansão da escola conta a favor da sua disseminação como direito, são um exemplo de enunciações da educação como direito vinculadas à incompreensão das funções hegemônicas reais não só da universalização como ideologia e da diferenciação como fato de estrutura, mas principalmente da relação de mútua constituição entre universalização e diferenciação, no capitalismo.

Pois bem, o que essas enunciações domesticadas de educação como direito tendem a ocultar? Elas ocultam que não é o propósito real de plena universalização 
(as mesmas possibilidades formativas escolares radicalmente para todos) o que move a história da expansão da escola. Ocultam que a diferenciação da escolarização não é um momento no processo de sua produção que tende a ser superado por meio de um automatismo do desenvolvimento histórico. Que o nexo constitutivo profundo, dialético, entre universalização (como ideologia e como fato, no que diz respeito à escolarização - diferenciada - de todos) e diferenciação (como a forma real de realização histórica da expansão e da cobertura territorial e populacional da escola) é o que constitui hegemonicamente o processo de disseminação da escola, como instituição social especializada, e da escolarização, como processo de institucionalização dos indivíduos, grupos e classes, sob o capitalismo. Essa ocultação é o que em parte viabiliza, por pelo menos um século, nos países capitalistas, mesmo no caso das nações econômica e politicamente periféricas, que a escola chegue a todos (ou tenda decisivamente nessa direção) sem que seja abalada sua capacidade de alocar diferenciadamente, na vida econômica, política e social, as classes, frações de classes, grupos e sujeitos. ${ }^{3}$

Portanto, ainda que a plena cobertura populacional e territorial da escola prossiga, em países como o Brasil, como um problema concreto central para a configuração da educação como direito, não há dúvida de que a questão educacional - ou seja, o modo como uma sociedade se interroga a respeito da educação como direito - precisa ser decisivamente relacionada ao desafio da unitariedade das condições de realização da escola e da escolarização, unitariedade de condições que não deve ser vista apenas como propósito objetivo de políticas, mas, antes, como uma espécie de critério de análise das condições atuais de realização da escola que nos possibilita problematizar o mais radicalmente possível as relações cotidianas vigentes na escola que temos.

Retornarei a essa questão, adiante, ainda que sem a profundidade e clareza desejada, para indicar aspectos de sua discussão e prática que me parecem centrais no debate sobre a formação dos trabalhadores na escola, hoje.

Voltando, por ora, à questão dos nexos constitutivos entre universalização e diferenciação, retomo a observação de que a compreensão dos sentidos profundos do movimento hegemônico de produção da escola, e das suas incidências sobre a

\footnotetext{
${ }^{3}$ Uma discussão mais detalhada sobre o modo particular como a diferenciação formativa persiste e se renova como meio por excelência de realização da universalização da escolarização, no Brasil, pode ser encontrada em Rummert, Algebaile e Ventura (2012).
} 
formação do trabalhador, requer a percepção de que parte de sua efetividade depende de que a diferenciação não seja percebida segundo seu peso, posição e funções hegemônicas reais nesse processo.

Evidentemente, a forma como se realiza a diferenciação ao longo da história e as feições por ela assumidas variam conforme as condições de formação de cada sociedade. Por exemplo, ela tende a formas sutis de diferenciação da formação escolar, na França, e a formas aberrantes de diferenciação da escola e da escolarização ${ }^{4}$ no Brasil. E, como um desdobramento inevitável disto, a percepção da diferenciação e do seu caráter na produção geral da escola também varia de sociedade a sociedade, sendo igualmente variadas as formas de sua dissimulação.

Em casos como o da França, a não percepção da diferenciação formativa efetivamente realizada pela escola, evidenciada por autores como Bourdieu (1998) e Sirota (1993), dependeu de uma impressionante padronização da oferta escolar e da escola como instituição, envolvendo todos os seus elementos materiais, funcionais e pedagógicos, inclusive o trabalho docente, o regime de trabalho e a remuneração do professor. Assim, a diferenciação formativa se deu fundamentalmente no interior do próprio sistema, das redes de escolas, dos programas formativos etc., mas em elementos sutis por meio dos quais os nexos entre a escola e as relações sociais dominantes são renovados e aprofundados, como os reforços ou desestímulos quase subliminares dos professores em relação ao uso da palavra em sala de aula por parte de crianças de famílias vinculadas a diferentes categorias sócio-profissionais dos pais (SIROTA, 1993), ou como os desencorajamentos em relação aos caminhos de prosseguimento nos estudos, ocultos ao ponto de serem percebidos como escolha do destino pelos próprios sujeitos (Bourdieu, 1998).

Em sentido contrário, no Brasil, como podemos ver em estudos clássicos como os de Beisiegel (1974) e Frigotto (2001), e como buscamos mostrar em trabalhos anteriores (Algebaile, 2009 e 2013), a diferenciação das condições materiais e funcionais das escolas, bem como das vias formativas que compõem concretamente a escolarização, envolvendo incisivamente os mais variados

\footnotetext{
${ }^{4}$ Com evidentes desdobramentos em termos de diferenciação da formação escolar. Mas me parece fundamental identificar que, neste caso, as variações nas condições materiais e funcionais das escolas, bem como nas vias formativas que compõem a oferta de escolarização, são aspectos precedentes (histórica e estruturalmente) com peso decisivo.
} 
aspectos objetivos e subjetivos, foi mantida com impressionante centralidade e segundo uma dinâmica de permanente renovação, acompanhando um processo simultâneo de intensificação e diversificação da diferenciação social.

$E$ é fundamental destacarmos aqui que essa forma de diferenciação - que tem como elemento histórico e estrutural precedente a brutal desigualdade dos prédios, dos recursos materiais, do financiamento, dos cursos, das jornadas escolares, das possibilidades de prosseguimento nos estudos, das formas de composição das equipes de trabalho, da remuneração profissional, dentre uma infinidade de aspectos que acabam por constituir as condições objetivas e subjetivas de realização da escola - não tem repercussões problemáticas apenas na formação escolar, em sentido restrito. Tem um efeito formativo igualmente problemático sobre todos aqueles que participam regularmente da realização da escola: profissionais, alunos, familiares, representantes comunitários, etc., pois tende a atingir as possibilidades de compreensão, formulação e atuação coletiva sobre os problemas materiais, funcionais, pedagógicos e políticos da escola, fomentando individualismo e concorrência onde e quando deveriam prevalecer noções e orientações compartilhadas; defesas corporativas onde e quando deveriam prevalecer projetos de agregação em torno de objetivos comuns; hierarquização onde e quando deveria predominar ao menos a tentativa de alguma horizontalidade.

Esse quadro decisivamente não unitário de realização da escola, portanto, cria dificuldades correspondentes de compreensão sobre as incidências da experiência escolar na formação da classe trabalhadora, com evidentes repercussões sobre os projetos e as ações comprometidas com transformações.

Assim, não é por acaso que as proposições de reforma educacional focadas na "correção" do professor e nas mudanças curriculares são as medidas de primeira hora propostas por inúmeros governos. Também não é por acaso que a atuação de parte dos sujeitos da escola tenda a discrepar, às vezes fortemente, com aquilo que eles pensam ou dizem pensar sobre as formas adequadas de ação. Isto ocorre porque as condições problemáticas e desiguais de realização da escola erodem cotidianamente as possibilidades de produção dos acúmulos coletivos necessários para que os diversos segmentos que atuam cotidianamente na realização da escola consigam pensar estrategicamente o que são, o que querem e como devem 
proceder para consegui-lo, e, na ausência de análises e programas próprios bem consolidados, as interpretações e programas que se projetam sobre a superfície dos problemas pautam com maior facilidade o debate a ação.

Não são poucas nem frágeis as formulações críticas que perceberam a centralidade desse problema. Mas creio ser suficiente trazer aqui um pouco das observações de Florestan Fernandes feitas a partir de sua intensa participação nos processos de elaboração e discussão de duas Leis de Diretrizes e Bases da Educação Nacional e do capítulo sobre educação na Constituição Federal de 1988, observações empenhadas em mostrar que nossas expectativas de mudança não deveriam se circunscrever às conquistas jurídicas ou às ações governamentais.

O importante, hoje, não é o que a nova lei poderá fazer para acabar com os vestígios de uma pedagogia às avessas, pervertida. É o que ela poderá ser para gerar, a partir de nossos dias, uma educação escolarizada fincada na escola e nucleada na sala de aula. Não basta remover os "excessos" de centralização, que substituem a relação pedagógica pela relação de poder. É preciso construir uma escola auto-suficiente e autônoma, capaz de crescer por seus próprios dinamismos. Conferir à sala de aula a capacidade de operar como o experimentum crucis da prática escolar humanizada, de liberação do oprimido, de descolonização das mentes e corações dos professores e alunos, de integração de todos nas correntes críticas de vitalização da comunidade escolar e de transformação do meio social ambiente. (Fernandes, 1989, p.23)

Não é nada fácil "construir uma escola auto-suficiente e autônoma, capaz de crescer por seus próprios dinamismos". Uma das dificuldades centrais, neste caso, reside no próprio fato de que a diferenciação intensa nas condições de sua realização produz distâncias importantes entre os e no interior dos diferentes segmentos (profissionais, alunos, responsáveis etc.) presentes no campo ampliado das relações (inevitavelmente formativas) que tecem a experiência escolar, posicionando-os em ângulos e momentos diferentes no que diz respeito às suas expectativas em relação às políticas educacionais, à escola, ao trabalho e à formação escolar. E nesse quadro, em que as diferenças de condições objetivas e subjetivas são tão variadas e intensas, torna-se muito difícil discernir quais são os elementos fundamentais das lutas, em que medida eles podem ser estrategicamente hierarquizados, quais podem efetivamente constituir o núcleo de 
questões comuns capazes de agregar sujeitos em torno da constituição de lutas coletivas.

Daí a necessidade de tomarmos essas diferenciações, na sua multiplicidade, como o fundamental objeto de estudo e intervenção em relação à formação dos trabalhadores, entendendo que a diferenciação da escola e a diferenciação da formação escolar que dela resulta não são um "estado" exterior aos sujeitos que possa ser superado por meio de políticas pontuais; são, antes, um fato de estrutura que incide sobre os sujeitos, formando-os como força social (constituída por fracionamentos relevantes) e, desse modo, condicionando suas possibilidades reais de se constituírem como uma força política capaz de se sobrepor aos fracionamentos que fragilizam suas possibilidades de atuação.

Nos quadros histórico e atual de realização da escola, no Brasil, os segmentos acima identificados - profissionais, alunos, familiares, grupos comunitários - podem conseguir se tornar uma força política orientada para a disputa das grandes questões do campo educacional, como verificamos no movimento histórico da constituição dos sindicatos docentes e nas lutas dos trabalhadores por escola e por educação, incluindo-se aqui obrigatoriamente com destaque o movimento estudantil que, dentre outras lutas, vem nos brindando mais recentemente com o surpreendente e avassalador movimento de ocupação das escolas. Mas, como claramente mostra Gramsci (2000b e 2002) em suas discussões sobre as forças sociais e políticas e seus processos de constituição, a persistência e intensificação das lutas de cada uma dessas forças, ao ponto delas produzirem em si próprias sucessivas modificações, depende de que elas não se mantenham como forças específicas, mais mobilizadas por questões de provisão ou por problemas corporativos do que pelas questões de grande política, obrigatórias para que haja efetiva disputa dos rumos da escola.

Portanto, o aspecto fundamental na discussão sobre a relação entre a diferenciação da escola e a formação dos trabalhadores na escola não diz respeito apenas aos seus efeitos em termos de formação escolar. $O$ aspecto fundamental é que a diferenciação é, em si, um mecanismo de formação, em sentido ampliado, que incide sobre nós de variados modos: plantando ilusões que atenuam e domesticam nossas lutas, fazendo-nos aceitar, reivindicar ou até mesmo propor (!) projetos mais coadunados do que percebemos com a escola estruturalmente 
desigual; dispersando-nos em problemas corporativos e dificultando as formas de agregação sem as quais professores, alunos, pais de alunos, demais profissionais etc. não desenvolvem como acúmulo coletivo as condições objetivas e subjetivas necessárias para disporem sobre a produção de um novo tipo de escola, de trabalho escolar, de formação escolar, intervindo de forma decisiva nessa produção.

\section{Sobre as possibilidades de uma formação de novo tipo na escola}

Se aceitarmos como válido o quadro de problematização até aqui apresentado, a questão das posições dos sujeitos nas relações escolares se coloca como central em qualquer discussão sobre a formação dos trabalhadores na escola, e isto tem implicações importantes para as pautas de estudo, de lutas e de ação desses sujeitos.

De fato, se a diferenciação escolar produz, para além de pontos de chegada desiguais, posições desiguais e dispersões que, desde o presente, impedem que os sujeitos mais diretamente vinculados à realização cotidiana da escola possam sobre ela dispor, um ponto de partida fundamental para o enfrentamento dessa condição desigual situa-se estruturalmente antes da formação escolar, em sentido restrito, ou seja, situa-se na formação mútua e em escala ampliada dos sujeitos que atuam na realização cotidiana da escola. E esse é um âmbito de formação que só pode sinalizar possibilidades transformadoras se forem instauradas experiências coletivas que, contrariando o fracionamento e hierarquização dos sujeitos, favoreçam a identificação e construção de aproximações, de objetivos comuns e de solidariedades capazes de fazer fermentar, por seus próprios dinamismos, projetos contra-hegemônicos de escola.

Tudo o que foi observado até aqui reforça, assim, a ideia de que lutas decisivas por uma formação escolar de novo tipo para os trabalhadores não se situam, imediatamente, no próprio plano da formação escolar, em sentido restrito. O núcleo de difusão dessas lutas se situa num âmbito bem mais complexo, no qual a escola se realiza cotidianamente como espaço de formação coletiva ampliada.

Não quero, com esta proposição, negligenciar ou desqualificar a discussão mais propriamente pedagógica relativa ao trabalho formativo da escola, mas 
defender que esta tende a se manter como uma questão de superfície se não enfrentamos com maior radicalidade a questão das relações por meio das quais a escola se realiza cotidianamente como um âmbito de formação ampliada de todos que dela participam.

Como alerta Thompson (2004, p. 10), "não podemos ter amor sem amantes", o que significa dizer que não há mudança fundamental na formação escolar que prescinda da formação daqueles sujeitos coletivos capazes de fomentá-la, definila, conduzi-la e, desse modo, realizá-la. E, assim como não há amor realizado por quem está fora da relação amorosa, o único sujeito coletivo capaz de realizar essa escola de novo tipo é aquele constituído pelos segmentos que efetivamente participam de sua feitura cotidiana, como os alunos, os responsáveis, os profissionais e os representantes comunitários.

Isto faz com que as condições atuais de realização da escola sejam um objeto primordial de estudo e de ação política, de modo a fomentarmos formas de relações que possam contrariar aquilo que nos tornamos ao sermos expostos à escola fragmentada e desigual.

Parece fundamental, neste caso, ampliar e coletivizar os estudos sobre as cisões internas da escola que parecem resultar dos atravessamentos entre nossa histórica diferenciação e as desagregações mais recentes (promovidas pela nossa ordem social desigual e por políticas educacionais que intensificam fracionamentos) entre os alunos e suas famílias e os profissionais da educação, entre estes e os demais profissionais atuantes hoje na escola, e entre esses diversos segmentos, uns em relação aos outros.

De outro lado, parece igualmente fundamental ampliar o debate sobre as formas mais recentes de resistência e luta que vêm afirmando a emergência de sujeitos políticos de novo tipo, capazes de colocar a luta por escola e por educação em um novo patamar histórico. Refiro-me aqui mais diretamente ao movimento de ocupação das escolas, ao longo do ano de 2016, que, de meu ponto de vista, está se constituindo como um dos principais movimentos, em nossa história, de abordagem da questão educacional como questão de grande política. Não tenho como tratar de forma aprofundada esta questão nos limites deste artigo, mas creio ser fundamental registrar a importância política e formativa desse movimento, no atual contexto. Observe-se, neste caso, o quanto esse movimento representa 
inovações e potências que, apesar de ainda não poderem ser avaliadas em termos de seus impactos e desdobramentos, podem e devem ser reconhecidas tanto por sua forma original (um movimento por educação fincado na escola e efetivamente protagonizado pelos sujeitos de direitos, com destaque para o peso decisivo dos alunos da educação básica) quanto por sua escala de realização (já que se realiza em escala nacional).

É preciso disputar incisivamente as possibilidades de conversar sistemática e regularmente sobre isto na escola e em todos os demais espaços de discussão sobre políticas públicas, conquistando o maior número possível de pessoas para essa conversa e apostando na constituição de práticas que ajudem a nos deslocar das posições fracionadas e hierarquizadas em que fomos colocados e que não raramente são por nós naturalizadas ou reforçadas. Conversas e práticas que nos coloquem de novos modos em relação à desagregação da experiência escolar de alunos e pais de alunos, promovida pelas políticas de aceleração de aprendizagem, pelos programas diversificados de formação que acontecem por dentro e por fora da escola, pelos novos fracionamentos entre formação geral e formação profissional, dentre outras medidas. Que nos coloquem de novos modos em relação à desagregação dos profissionais da educação devido às políticas de responsabilização, às variadas medidas que concorrem para a diferenciação de posições profissionais, salários e regimes de contratação dentro de uma mesma escola, bem como às práticas de não consagração do tempo de trabalho escolar ao trabalho coletivo.

É preciso conversar sobre o "repovoamento" profissional da escola no contexto de difusão de políticas e programas sociais vinculados à escolarização, identificando as novas hierarquias e intervenções na escola feitas por essa via, mas também nossas dificuldades em ressignificar isto, indagando sobre as possibilidades de apreendermos a nova configuração dos quadros profissionais vinculados à escola como oportunidade de uma experiência interdisciplinar que altere o ponto de partida de cada profissão isolada, que abale seus corporativismos e invista os diferentes segmentos da tarefa de experimentar, fortalecer e fazer contar a favor da escola essa oportunidade contraditória de um olhar reconstruído pela experiência compartilhada. 
Quem sabe daí consigamos discutir sobre o que fazemos e o que podemos fazer em relação às frações do tempo escolar possíveis de serem fecundadas pelo trabalho associado.

O maior desafio de pensamento e ação em relação à formação dos trabalhadores na escola se situa no plano das relações reais entre os diferentes segmentos que atuam cotidianamente na produção da escola. Sem a conversa e a prática sistemática e regular sobre isto - sobre o que nos tornamos sob as condições de trabalho e estudo que nos legaram, e sobre o que podemos nos tornar quando interferimos cotidianamente nessa realidade, disputando sua forma, seu conteúdo e seus sentidos -, não desenvolveremos formas mais claras de entender, falar e dispor coletivamente sobre essa realidade escolar que nos assola e assujeita, fazendo com que, mesmo capazes de discutir brilhantemente a escola, mantenhamo-nos incapazes de tocá-la.

A rigor, uma escola capaz de "crescer por seus próprios dinamismos" jamais surgirá como resultado direto de uma política estatal. Ela só poderá crescer desse modo se, nela, a classe trabalhadora estiver, como lembra Thompson (2004), "presente em sua própria formação". E isto implica produzir, de algum modo, certamente contra a correnteza, as possibilidades de que a escola e a sala de aula operem como um "experimentum crucis" em todos os segmentos envolvidos com a sua feitura cotidiana, aproximando o que está disperso e hierarquizado, coletivizando o que está segmentado, construindo pontos comuns capazes de confrontar as relações concorrenciais a todo dia replantadas.

Por isso, a formação dos trabalhadores na escola é, para nós, profissionais da educação, um dos mais espinhosos e, no entanto, um dos mais fundamentais desafios. Porque, na escola, a formação dos trabalhadores, a cada dia e por longos anos para todos nós, ocorre como uma experiência simultânea de formação escolar, de "formação no trabalho" e de "formação nos movimentos sociais". Este lugar - a escola - é isto, e é por essa sua condição que o centro de sua disputa não está apenas na sua especialidade, mas, antes, nesse ponto ímpar de atravessamento, simultaneidade e mútua produção de experiências formativas. Ou nos damos conta disto e nos jogamos de corpo e alma nesse âmbito de formação coletiva a partir do qual a escola se define, ou passaremos mais 100, 200, 500 anos discutindo e tentando intervir na formação escolar enquanto ela nos escapa. 


\section{Referências Bibliográficas}

ALGEBAILE, Eveline. Escola pública e pobreza no Brasil: a ampliação para menos. Rio de Janeiro: Faperj, Lamparina, 2009.

A expansão escolar em reconfiguração. Revista Contemporânea de

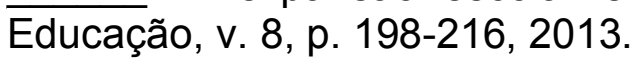

BEISIEGEL, Celso Rui. Estado e Educação Popular: um estudo sobre a educação de adultos. São Paulo: Pioneira, 1974.

BOURDIEU, P. A escola conservadora: as desigualdades frente à escola e à cultura. In: NOGUEIRA, M. A.; CATANI. A. (orgs). In: Escritos de educação. Petrópolis: Vozes, 1998.

CASTEL, Robert. As metamorfoses da questão social: uma crônica do salário. Petrópolis: Vozes, 1998.

DONZELOT, Jacques. A polícia das famílias. São Paulo: Graal, 2001.

FERNANDES, Florestan. O desafio educacional. São Paulo: Cortez e Editora Autores Associados, 1989.

FRIGOTTO, Gaudêncio. A produtividade da escola improdutiva: um (re)exame das relações entre educação e estrutura econômico-social capitalista. $6^{a}$ edição. São Paulo: Cortez, 2001.

GRAMSCI, Antonio. Cadernos do cárcere. Volume 2. Os intelectuais. O princípio educativo. Jornalismo. Rio de Janeiro: Civilização Brasileira, 2000a.

. Cadernos do cárcere. Volume 3. Maquiavel. Notas sobre o Estado e a política. Rio de Janeiro: Civilização Brasileira, 2000b.

. Cadernos do cárcere. Volume 5. O Risorgimento. Notas sobre a história da Itália Rio de Janeiro: Civilização Brasileira, 2002.

PETITAT, André. Produção da escola/produção da sociedade: análise sóciohistórica de alguns momentos decisivos da evolução escolar no ocidente. Porto Alegre: Artes Médicas, 1994.

RUMMERT, Sonia Maria; ALGEBAILE, Eveline; VENTURA, Jaqueline. Educação e formação humana no cenário de integração subalterna no capital-imperialismo. In: SILVA, M. M.; EVANGELISTA, O.; QUARTIERO, E. (Orgs.). Jovens, Trabalho e Educação: a conexão subordinada de formação para o capital. Campinas: Mercado de Letras, p. 15-70, 2012.

SIROTA, Regine. A escola primária no cotidiano. Porto Alegre: Artes Médicas, 1993. 
THOMPSON, Edward Palmer. A formação da classe operária inglesa I. A árvore da liberdade. $4^{\mathrm{a}}$ Ed. Rio de Janeiro, Paz e Terra, 2004.

A formação da classe operária inglesa II. A maldição de Adão. $4^{\text {a }}$ Ed.Rio de Janeiro, Paz e Terra, 2002a.

A formação da classe operária inglesa III. A força dos trabalhadores. $3^{a}$ Ed. Rio de Janeiro, Paz e Terra, 2002b.

A miséria da teoria ou um planetário de erros Rio de Janeiro: Zahar, 1981.

VARELA, Julia; ALVAREZ-URÍA, Fernando. Arqueología de la escuela. Madrid: La Piqueta, 1991. 